\title{
Entre Venus y Marte: el viaje del héroe en Desertor ${ }^{1}$
}

\section{(Between Venus and Mars: The Journey of the Hero in Desertor)}

\section{Grethel Ramírez Villalobos ${ }^{2}$}

Universidad Nacional, Costa Rica

resumen

En este artículo se estudia la figura del héroe en la novela Desertor, del costarricense Juan Ramón Rojas. Este relato tiene su ambiente en El Salvador y analiza algunos de los principales hechos históricos de la década de 1980. El protagonista del relato se ve impulsado a revisar sus propias convicciones políticas y emprende un viaje, que resulta análogo a los periplos de los héroes mitológicos. A partir del examen de la conformación del héroe, se discuten los simbolismos literarios y los principales asuntos tratados en la novela.

\section{abstract}

This article addresses the figure of the hero in the novel Desertor, by the Costa Rican Juan Ramón Rojas. It takes place in El Salvador and analyzes some of the main historical events of the 1980s. The protagonist is forced to review his own political convictions and sets out on a journey analogous to those of mythological heroes. Considering the analysis of the conformation of the hero, literary symbolism and the main topics of the novel are examined.

Palabras clave: narrativa costarricense, novela centroamericana contemporánea, literatura y mito, viaje del héroe, conflicto armado y literatura

1 Recibido: 21 de marzo de 2014; aceptado: 20 de abril de 2014.

2 Escuela de Literatura y Ciencias del Lenguaje: Correo electrónico: prof.grethel@gmail.com

$$
L_{\text {etras }} 55 \text { (2014), ISSN 1409-424X; eISSN 2215-4094 }
$$


Keywords: Costa Rican narrative, contemporary Central American novel, literature and myth, journey of the hero, armed conflict and literature

«La crueldad de la guerra infame se engullía, como Polifemo a los hombres de Ulises, las vidas más jóvenes».

Desertor, Juan Ramón Rojas

\section{Introducción}

El objetivo de este estudio consiste en analizar la figura del héroe en la novela Desertor (2009), de Juan Ramón Rojas (Costa Rica, 1950). Para ello, se emplea un modelo explicativo básico, inspirado por algunas nociones propias de la teoría de la ficción literaria y otras categorías procedentes del psicoanálisis, en particular, relacionadas con la comprensión del valor socio-cultural del mito, los simbolismos del viaje y la construcción de prototipos.

La novela versa sobre un guerrillero, Mauricio Reyes, que se ve empujado, por causa de una situación traumática, a formar parte del conflicto armado salvadoreño. Más tarde, cuando el protagonista se convierte en adulto, deserta de la causa política por motivos amorosos e ideológicos. En términos históricos, la novela trata acerca de los eventos en torno al levantamiento del Ejército Revolucionario del Pueblo (por sus siglas, ERP), la alianza con otras agrupaciones de izquierda y la constitución del Frente Farabundo Martí para la Liberación Nacional (FMLN).

El tratamiento del conflicto armado se funda en una visión escéptica de las aspiraciones revolucionarias. Tal visión es parte de una sensibilidad estrictamente contemporánea, incluso, reciente. Tras la constatación de la barbarie de ambos bandos, el fracaso de los procesos revolucionarios, la caída del socialismo real y la intensificación del individualismo, ha nacido una nueva percepción acerca de conceptos como «compromiso político», «búsqueda del perfeccionamiento social» $\mathrm{y}$ «orientación ética del individuo». 
Puesto que el papel de héroe recae en la figura de un desertor de la guerrilla, conviene señalar que la novela nos propone, en sentido preciso, la historia de un antihéroe. Más allá de cualquier nominalismo inoportuno, bastará con acotar que, como ocurre en casi toda la gran novelística del siglo xx, el personaje central se caracteriza menos por sus hazañas y virtudes, y más por su humanidad, inconsistencia y fracasos. El personaje de Mauricio Reyes remite, desde luego, a la figura del traidor, sin que ello implique, en la novela, ninguna connotación negativa. Por el contrario, su decisión política es presentada como sensata, pues la heroicidad del personaje proviene de su propia caída y de la capacidad para sobreponer la búsqueda personal a la estéril lucha política. Al final del relato, su ejemplo de vida introduce la duda entre otros guerrilleros.

Ferrero Hernández indica que el traidor, en tanto carácter literario, abre diversos debates en torno a la valoración ideológica de las posiciones políticas anómalas:

La figura del traidor es, en realidad, una visión negativa del héroe desde la teoría del buen gobierno. El traidor ha sido visto siempre como el personaje taimado, mezquino, cuyos intereses priman por encima de lo colectivo. Los cambios políticos han convertido, de hecho, a muchos traidores en héroes nacionales. Por otra parte, hemos de considerar dentro del tema del traidor el del rebelde, el de quien pone en tela de juicio la figura del gobernante, los principios de un estado en el que no cree $^{3}$.

El autor ha aprovechado este complejo prototipo literario para discutir acerca de las condiciones ideológicas tras los conflictos armados enlaregión. La fábula deltraidor permite plantear acuciosas reflexiones respecto de la degeneración de cúpulas políticas y el temprano ocaso de las utopías. Mediante la historia de un desertor, la novela evidencia los esquematismos de la época. Los bandos en pugna, contrapuestos

3 Cándida Ferrero Hernández, Textos de literatura europea y tradición clásica (Barcelona: Servicio de Publicaciones-Universidad Autónoma de Barcelona, 2006) 45. 
en sustancia según el entendimiento de la década de 1980, aparecen ahora, según la valoración del texto, como dos secciones de una misma realidad: ambición, ceguera, destrucción y muerte.

Otros escritores contemporáneos, como Carlos Cortés (Costa Rica, 1962), han procurado situar la semilla del escepticismo en el momento mismo de los enfrentamientos. Obras como Cruz de olvido (1999) se preguntan acerca del nacimiento del desencanto y lo datan en la primera época. En Desertor, el fervor revolucionario de juventud se retrotrae con la llegada de la vida adulta.

En Desertor, el narrador se detiene en la vida cotidiana de los guerrilleros, según la conoció el autor durante su labor como corresponsal de prensa. La descripción de las angustias va de la mano con la pregunta acerca de la manipulación de estos hombres. Ahora bien, el texto es contundente al afirmar que la distorsión de la verdad, la justicia y los ideales no es un acción privativa de la cúpula revolucionaria, sino que constituye el principal medio del poder político, en general.

\section{La novela frente a la historia}

Como lo señala Martínez Peñate ${ }^{4}, 1980$ fue un año decisivo en la historia de El Salvador, pues aunque estuvo precedido por un tenso periodo de inestabilidad, supuso el inicio de la insurrección y el comienzo de la extensa guerra civil, que no finalizó sino en 1992 y cobró la vida de miles de personas. En marzo de ese año, el asesinato de Óscar Arnulfo Romero, arzobispo de San Salvador, quien había exigido a Estados Unidos retirar el apoyo económico y militar al régimen y el cese del autoritarismo, se convirtió en un símbolo de la confrontación.

Los primeros años impusieron un hito, pues la serie de eventos represivos protagonizados por instancias del Estado y organizaciones

4 Oscar Martínez Peñate, El Salvador. Historia general (San Salvador: Nuevo Enfoque, 2002) 154-155. 
paramilitares, dio lugar a la confluencia de los grupos de izquierda y la impetuosa respuesta armada. Las Fuerzas Populares de Liberación, el Ejército Revolucionario del Pueblo, el Partido Revolucionario de los Trabajadores Centroamericanos, la Resistencia Nacional y el Partido Comunista Salvadoreño se unificaron mediante la Dirección Revolucionaria Unificada (DRU), formada en mayo de 1980. En enero de 1981, el FMLN lanzó una ofensiva general y llamó a la insurrección. Los revolucionarios no alcanzaron el poder; a partir de entonces, la represión fue cruenta y el conflicto armado se precipitó durante más de una década.

Martínez Peñate ${ }^{5}$ subraya un dato: en setiembre de 1981, la Comisión de Derechos Humanos de El Salvador estimó que un total de 32,000 civiles habían sido asesinados por fuerzas gubernamentales o por escuadrones de la muerte vinculados al Ejército. Por esas fechas, D’Aubuisson anunció la fundación del Partido Alianza Republicana Nacionalista (ARENA), y posteriormente, su postulación como candidato presidencial. Al término del conflicto armado, la cifra de muertos y desaparecidos aumentó casi a una centena de miles.

Uno de los hechos históricos que anima la fábula de la novela Desertor es la Masacre de El Mozote. Este trágico suceso, acaecido en 1981, supuso uno de los episodios más cruentos del conflicto. Como parte de la incursión del Batallón Atlacatl, de la Fuerzas Armadas, fueron asesinados varios cientos de civiles en la localidad del Departamento de Morazán. La purga política tras el levantamiento, la barbarie de la represión militar y el exterminio familiar dan origen a la conciencia del protagonista de la novela.

Otro evento histórico de singular importancia es recordado en la novela de Rojas, se trata de la invasión de los recintos de la Universidad Centroamericana José Simeón Cañas durante la madrugada del 16 de abril de 1989. Este hecho culminó con el asesinato de varios jesuitas, divulgadores de las ideas políticas de la teología de la

5 Martínez Peñate, 155. 
liberación. Cabe destacar que la novela de Rojas no alude al final de la guerra civil.

En sentido estricto, el relato empieza en 1981, con la masacre de El Mozote, época en que el personaje central cuenta 17 años de edad y se convierte, primero, en huérfano y luego, en proscrito. La narración concluye cerca de 1990, cuando Mauricio muere, presa de las contradicciones. La novela no trata el periodo de posguerra, pues se circunscribe a los años de desarrollo del conflicto armado; no obstante, introduce una sensibilidad típica de la literatura de posguerra, pues se pregunta respecto del descreimiento, la similitud entre los bandos en contienda y la posibilidad de imaginar utopías particulares, privadas y elementales en una región destruida.

Si bien determinada por un alto contenido histórico, la novela de Rojas ofrece pocos indicios referenciales explícitos, aparte de los ya mencionados. En mi opinión, el más importante de ellos alude al fusilamiento del poeta Roque Dalton: «Por diferencias de enfoque sobre cómo llevar adelante la lucha revolucionaria, sus compañeros, algunos de ellos incluso al frente del EPR, lo asesinaron en $1975 »^{6}$.

Estas aseveraciones del narrador dotan al lector de unas referencias autorizadas precisas, con las cuales comprender la realidad histórica propuesta en la novela; por lo demás, corresponden a cabalidad con otros elementos paratextuales, como el epígrafe inicial, que conducen al lector hacia determinadas valoraciones respecto de la manipulación ideológica, la mentira artera y el poder.

En estas primeras aproximaciones, la necesaria distinción entre la realidad histórica y la comprensión literaria. Como ha señalado Doležel ${ }^{7}$, los textos literarios constituyen un medio semiótico, capaz de expresar estados posibles-no reales determinados por la conciencia artística, la imaginación y la ideología. La conformación de estos

6 Juan Ramón Rojas, Desertor (San José: Uruk, 2009) 65. En adelante, las citas de la novela se consignan entre paréntesis.

7 Lubomir Doležel, «Mímesis y mundos posibles», Antonio Garrido (comp.), Teorías de la ficción literaria (Madrid: Arco/Libros, 1997) 82-83. 
estados posibles no depende de los procesos de mímesis, sino de los marcos de referencia interna, creados por los distintos mecanismos dispuestos en el texto.

La novela de Rojas propone una visión particular del conflicto armado salvadoreño. Se funda en la reescritura en clave escéptica de los principales sucesos históricos. Por ello, elcentro de interés descansa en la figura del desertor, representada de modo heroico en el texto literario. En sentido estricto, el narrador de Desertor atribuye la muerte de Roque Dalton a los conflictos internos delEPR, en específico, a las polémicas respecto del liderazgo de Sebastián Urquilla (pseudónimo empleado por Alejandro Rivas Mira, fundador y cabecilla del grupo) y los procedimientos empleados en la lucha revolucionaria.

El narrador del relato, una voz omnisciente, describe a Mauricio como un hombre receloso de los fines de la guerrilla. Si bien el personaje considera despótico al gobierno y atroz a la guerrilla, su decisión de desertar es motivada, en principio, por razones sentimentales. El amor por Aurora Palacios, una periodista, lo impulsa. La amada se caracteriza por las contradicciones, pues simpatiza con la guerrilla, aunque trabaja para un diario conservador dirigido por el gobierno del presidente Crisanto.

El enamoramiento adquiere un simbolismo político, pues refiere a la ambigüedad de postura experimentada por el propio protagonista. En tal sentido, Aurora es una formación inconsciente, que expresa las ansías del héroe. El amor por ella, el abandono de la guerrilla y la adquisición de conciencia a propósito del adoctrinamiento constituyen procesos análogos. De la mera circunstancia sentimental, el protagonista evoluciona hacia la revisión de sus ideales políticos. En consecuencia, emprende una exploración intelectual, que lo separa de los aprendizajes de juventud y dirige a la consecución de una conciencia adulta, esto es, propia, libre y ensimismada. 


\section{La constitución del héroe}

La exploración de la conciencia y el desplazamiento físico permiten que el hombre adquiera nuevos conocimientos. La experiencia de sí mismo y del mundo amplía los límites de la comprensión y hace posible la autoafirmación. Freud cifraba en el Complejo de Edipo un proceso indispensable, que convertía a los miembros de la especie en seres sociales. Como observaron luego otros pensadores, los esquemas del mito se repiten, incluso en las comunidades modernas, porque reelaboran aspectos esenciales de la conformación psíquica y socio-cultural.

Eliade correlacionó los mitos con los rituales, toda vez que los primeros dan sentido a la experiencia básica, que merece ser recordada a través del tiempo: «El mito cuenta una historia sagrada; relata un acontecimiento que ha tenido lugar en el tiempo primordial, el tiempo fabuloso de los "comienzos" $»^{8}$. La iniciación en la vida consciente, adulta y libre requiere de un proceso que separe al hombre de lo aprendido y conocido. Con frecuencia, este proceso ha sido imaginado mediante el motivo del viaje.

Los viajes separan lo familiar, proveen incógnitas y arrojan a lo incierto; en tal sentido, dotan al personaje de una serie de nuevas visiones. Por ende, el mito (rito y viaje) funciona como una ayuda espiritual que permite al sujeto separarse del pasado, superar la etapa infantil y apreciar la complejidad de las cosas ${ }^{9}$. En un recordado tratado suyo, Joseph Campbell concluye: «El héroe, por tanto, es el hombre o la mujer que ha sido capaz de combatir y triunfar sobre las limitaciones históricas personales y locales y ha alcanzado las formas humanas generales, válidas y normales» ${ }^{10}$.

8 Mircea Eliade, Mito y realidad (Madrid: Guadarrama, 1968) 18.

9 Carlos García, Mitos, viajes, héroes (México: Fondo de Cultura Económica, 2011) 25.

10 Joseph Campbell, El héroe de las mil caras. Psicoanálisis del mito (México: Fondo de Cultura Económica, 2006) 26. 
Según explica Campbell, la aventura del héroe, tanto tradicional como moderno, consta de tres elementos: separación, iniciación y retorno. Estos constituyentes del mito hallan consonancia en los distintos ritos de iniciación, comunes a gran parte de las religiones. En el desarrollo del mito, representado mediante el simbolismo del viaje, «el héroe inicia su aventura desde el mundo de todos los días hacia una región de prodigios sobrenaturales, se enfrenta con fuerzas fabulosas y gana una victoria decisiva $»^{11}$.

Tal triunfo del héroe suele estar expresado como adquisición de conocimiento, como reafirmación de sus propias posibilidades, como superación de los temores y límites impuestos por un medio determinado, como paso de la vida doméstica e infantil a la conciencia amplia y adulta. Tras superar las pruebas, el héroe retorna de su misteriosa aventura con la capacidad de otorgar dones a sus iguales, esto es, de compartir una nueva comprensión de las circunstancias comunes a los hombres.

En la novela, el protagonista no es imaginado bajo los cánones del héroe mitológico, aunque comparte algunos rasgos con este. Tanto más determinado por el patetismo, Mauricio enfrenta una aventura interior, relativa a sus convicciones políticas. Este personaje transita por selvas, campos y poblados a la vez que examina sus ideales. La prueba a la que se ve sometido es de carácter ideológico, pues se ve dividido entre dos búsquedas contrapuestas: la consecución del bien común o del bien individual. El temor al acto egoísta pesa sobre la conciencia del protagonista. Claudicar de los ideales revolucionarios equivale a renunciar a los preceptos aprendidos en la adolescencia, supone renegar de lo familiar y primigenio. La amenaza del castigo recuerda el profundo terror ante la ruptura edípica. Adoctrinado en la juventud y determinado por los horrores de la guerra, Mauricio duda respecto de la posibilidad de apartarse de la guerrilla y seguir

11 Campbell, 35. 
su impulso amoroso, de atender su propio interés sin cuidarse del bienestar de los demás.

\section{Primer paso: la partida}

En el primer momento de la aventura del héroe, la partida, el personaje goza de una vida ordinaria y de protección en el entorno familiar; la insatisfacción ante lo habitual y la curiosidad lo impulsan a salir en busca de un mundo distinto y de nuevas experiencias; desde luego, el miedo a lo desconocido y la culpa lo refrenan ${ }^{12}$. En Desertor, el protagonista, un guerrillero y músico de escasos veinticinco años, se enamora perdidamente de Aurora. Tras varios meses de pensar en una forma segura de huir, toma la decisión de abandonar la guerrilla para explorar un mundo totalmente diferente al que conoce.

Mauricio debe olvidarse de sus primeros ideales políticos ymiedo (convertirse en desertor es castigado con muerte). El desencanto y la preparación de un plan adecuado se convierten en los motores de su salida de la guerrilla:

Es el momento, meditó Mauricio Reyes, apartando la manta que le cubría el rostro. Abrió los ojos despacio, temeroso de que su vista chocara con la de algún compañero insomne [...]. Ansioso había esperado el plazo de una semana atrás para salir del campamento y de la opresión que le mantenía atado a una existencia sin futuro [...]. Desertar era el único camino que le quedaba. Al hastío de un conflicto bélico que cada día le estrechaba más los horizontes [...] se sumaba el anhelo de reunirse con Aurora Palacios (11-12).

Mauricio Reyes experimenta «la llamada a la aventura» ${ }^{13}$. Esta circunstancia se representa mediante el descubrimiento de Aurora. Ella le brinda la fuerza que no tenía antes, la capacidad de imaginar el bienestar propio y escapar del sacrificio altruista, una exigencia de los líderes revolucionarios a la que se vio destinado desde joven:

12 Campbell, 52-93.

13 Campbell, 53. 
En plena adolescencia, el destino le marcó abruptamente un camino jamás imaginado y, muchos años después, seguía igual, amarrado a ese destino, sin autonomía para correr sus propios riesgos, explotar sus fortalezas, ejercer libremente su propia individualidad (13).

Reyes no sucumbe con facilidad a la aventura, pues el arraigo en la guerrilla, una familia para el protagonista, dificulta la huida y consecuente separación de los ideales de juventud. En estos términos, el personaje es presa de la «negativa del llamado» ${ }^{14}$. Mucho antes de decidirse a huir, le personaje medita respecto de su condición. Entre el primer y el segundo encuentro con Aurora, transcurren tres años. Este periodo de distanciamiento entre el guerrillero y la amada intensifica el sentimiento de soledad en Mauricio. El momento decisivo lo constituye en idilio en Perquín, lugar donde los enamorados tropiezan y hacen el amor. Esto suceso provoca que Mauricio se obsesione con la amada y decida huir:

Recostada en su colchoneta, Aurora continuaba sin conciliar el sueño. Calculó que sería cerca de la medianoche. [...] Observó entre la penumbra una persona que se acercaba cautelosa, caminando como si levitara para no hacer ruido con sus pies descalzos. [...] y divisó la silueta de Mauricio (131).

Si bien la idea de vivir como un civil al lado Aurora le resulta tentadora, también es cierto que Mauricio quiere escapar de la guerrilla por causa del tedio, el agotamiento intelectual, el desencanto ideológico y el escepticismo respecto de la cúpula izquierdista. El protagonista está en desacuerdo con el proceder del ERP: «Su militancia en la guerrilla había cumplido su ciclo definitivo. Carecía de voluntad para seguir fingiendo y aparentando abnegación por una lucha y una organización de las que cada día se sentía más distante y desafecto» (21).

14 Campbell, 61. 
Con frecuencia, en los relatos antiguos y mitos, es determinante, en el primer paso hacia la aventura, la ayuda sobrenatural ${ }^{15}$. Ciertas fuerzas extraordinarias alientan al héroe a dejar atrás su hogar en pos de un beneficio particular, que acabara por definir su propio carácter. Este impulso se corresponde, en ocasiones, con un don o surge como resultado del encuentro con una divinidad o ser extraordinario. En el caso de Mauricio, la ayuda no proviene de un ente sobrehumano, sino del fugaz idilio con la amada: «Dios también es Aurora que había aparecido milagrosamente en el momento oportuno» (31).

El hecho de estar con ella y luego verse separado de su felicidad, reducido al combate, lo marca: «[...] iba surgiendo un nuevo Mauricio, arisco y desconocido. Después de ser un hombre alegre, servicial, locuaz, siempre junto a la guitarra [...] pasó a ser una persona taciturna, callada, inactiva, hipocondríaca» (19). El mal de amor destruye a Marte, lo reduce a la miseria; tras años de juventud perdida en el frente de guerra, Eros lo torna sensible, melancólico y egoísta.

Durante la noche del domingo, Mauricio huye. Empieza un nuevo periodo, que corresponde en lo simbólico con el primer día de la semana y la creación. El protagonista avanza en el viaje, pues completa «el cruce del umbral»: «Con las personificaciones de su destino para guiarlo y ayudarlo el héroe avanza a su aventura hasta que llega al "guardián del umbral" a la entrada de la zona de la fuerza magnificada», explica Campbell ${ }^{16}$.

Reyes huye del campamento, no sin antes meditar sobre la estrategia que debía llevar a cabo para no ser descubierto. En la huida, el protagonista experimenta una serie de incidentes que lo hacen dudar de su decisión, pero que también le permiten cobrar valor para atravesar el umbral. Dicho umbral está circunscrito, en la novela de Rojas, por el río Torola, límite entre el territorio invadido por la guerrilla y las regiones controladas por el ejército del presidente Crisanto.

15 Campbell, 70.

16 Campbell, 77. 
Este territorio, de implicaciones políticas, es bien conocido por Mauricio. El periplo por la selva demora dos días, lo cual establece un simbolismo respecto del dilema ético-político vivido por el protagonista. En la travesía hacia el río Torola, Reyes enfrenta diversas situaciones que actúan como pruebas: «Caminó toda una madrugada larga e intensa, durante la que no dejó de debatirse entre un doble sentimiento de alegría y nostalgia, y un latente temor ante el horizonte borroso que lo esperaba» (26).

Así, la lluvia le impide caminar con libertad, demora su avance y agota su espíritu; también un escondite que elige el lunes para refugiarse mina su voluntad: «La oquedad, de unos dos metros de largo por uno de ancho y cuyas paredes porosas e irregulares servían de casa a una nutrida población de arañas, lombrices, ciempiés, grillos y otros animalejos extraños que se asomaban por las gritas que se abrían suaves entre la tierra mojada» (28) ofrece una alegoría de la opresión interior y la intensificación del sentimiento de culpa que lo embargan.

Tanto el hambre como el calor son factores que dificultan la huida de Mauricio, son pruebas que el héroe debe superar mediante el coraje y la confirmación de su resistencia y aptitudes. El protagonista persigue un nuevo ideal, tiene una luz que lo impulsa a salir de la selva y cruzar el río, aunque no tenga idea de cuál será su destino: «Pero sobre todo, pensaba en Aurora, que, cual faro, lo guiaba desde lejos» (30). El motivo literario es antiguo y remite a Beatriz, guía de Dante en la Comedia divina, belleza que eleva el espíritu, amor que promueve el perfeccionamiento, mujer salvadora que conduce por «un nuevo sendero» (31).

El tránsito por el río Torola representa el paso de Mauricio entre dos vidas. Aunque el lector pueda percibir la partida como un tipo de renacimiento y redención del personaje, desde el inicio de la obra, el narrador advierte que el destino del héroe podría acabar mal: «Cayó algunas veces y se levantó nuevamente. Pero en un descuido resbaló, perdió el control y rodó y rodó, chocando con piedras y troncos 
hasta caer en una playita de arena negra, que acariciaban las aguas amarillentas del río» (32).

Antes de cruzar el río, que lo llevará al «vientre de la ballena» ${ }^{17}$ -concebido en esta novela como un bosque, donde Mauricio pierde la conciencia y se siente protegido-, Reyes experimenta un momento de bienestar, un «estado de nirvana», que le permite conocer la gracia, olvidar las desgracias vividas y dejar atrás la mala conciencia que le provocado el abandono de los ideales revolucionarios: «Se arrodilló. Puso las palmas de las manos hacia el cielo haciendo cruz con sus brazos para dar gracias a Dios, con fervor. Oró por la paz y la vida de todos los salvadoreños» (33).

Este pasaje podría dar lugar a impresiones puntuales, pues el lector puede entender que el protagonista ha hallado en remanso ante el conflicto armado; sin embargo, el narrador procura desmentir rápidamente esta idea: «Unos disparos de ametralladora, sin embargo, lo hicieron volver abruptamente a la realidad y salir del trance en el que levitaba plácidamente su alma. Se percató de que se encontraba en grave peligro» (33).

Reyes cruza el río bajo una lluvia de disparos de la guerrilla y del ejército, los primeros tratan de asesinar al desertor, mientras que los segundos creen ser objeto de un ataque. La nueva conciencia política de Mauricio, ajena a los esquematismos ideológicos y cifrada en la búsqueda de la felicidad - una visión desencantada, liviana, posmoderna, apolítica o centrada en los individuos, según se la juzgue-, no se corresponde ya con ninguno de los bandos en conflicto.

En la orilla del río, Mauricio penetra en el «vientre de la ballena», el cansancio y las heridas lo hacen perder la conciencia sin percatarse de que ha quedado en manos del enemigo: «Tumbado sobre la arena, sin la mochila ni el cuchillo, perdido en el último tramo de su huida, escuchó voces nuevamente de gente que hablaba cerca, de personas que no podía identificar. No tenía fuerzas para reaccionar y

17 Campbell, 88. 
preguntar de qué se trataba todo aquello y qué pretendían hacer con él» (34-35).

\section{Segundo paso: la iniciación}

Según propuso Campbel1 ${ }^{18}$, la iniciación del héroe no se da hasta que cruza el umbral y logra salir del vientre de la ballena. Justo en este instante, principia el periodo de las pruebas más intensas, aquellas en las que el héroe se encuentra con la diosa, confronta a la mujer como tentación, se reconcilia con el padre, vive la apoteosis y disfruta de la última y mayor gracia.

Mauricio comienza a enfrentar el periodo de pruebas una vez que es rescatado por la milicia. Los militares lo hallan inconsciente y apresan; luego, es llevado a una especie de cárcel, donde lo alimentan e identifican como Mauricio Reyes, el cantante y guitarrista de Los Rebeldes, ungrupo que había fundado durante su vida como guerrillero. Desde el momento en que cruza el río Torola, Reyes será visto por todos, inclusive por el narrador del relato como «el desertor».

Esta clasificación cambia su vida para siempre y constituye la prueba más difícil que deba enfrentar. El acto de Mauricio es incomprensible en el mundo de la guerra, Marte rendido ante Venus; por ello, su identidad se ve trastocada. Ahora, Mauricio es otro hombre, ha dejado de de ser el músico y soldado valiente de la guerrilla para convertirse en un desertor que pide misericordia al gobierno: «[...] el desertor respondió con una mirada impotente, de fiera enjaulada, ensayando una sonrisa que apenas se dibujó forzada en sus labios» (40).

Tan definitiva prueba nunca podrá ser superada en su totalidad por el protagonista: «Por sobre el dolor físico, lo aterraba ahora la confirmación de ser prisionero del Ejército; lo turbaba no contar con el amparo de nadie, lejos de la insurgencia que fue su apoyo y su protección por muchos años» (43). Privado de libertad, Mauricio es objeto de torturas y vigilancia permanente.

18 Campbell, 94-178. 
En la capital, el protagonista es sometido al escarnio y empleado con propaganda de disuasión. Durante una conferencia de prensa organizada por las autoridades, Reyes es obligado a relatar cómo huyó de la barbarie de la guerrilla con el propósito de obtener asilo y protección del gobierno. Más tarde, se publica un artículo supuestamente escrito por Reyes, en que reniega de la causa revolucionaria. La degradación de este héroe patético, condenado a sufrir como resultado de su renuncia a la maquinaria bélica, que lo engulle hasta la muerte, es incesante. Como parte de la farsa gubernamental, Mauricio debe enfrentar la inserción como civil en el barrio de Zacamil, un bastión rebelde, donde los insurgentes lo podrían reconocer y asesinar fácilmente.

Aunque Mauricio trata de integrarse a la comunidad, se muestra incapaz de vivir en una nación dividida, en la que ambos bandos le resultan igualmente crueles. El tedio lo embarga: «[...] no cocinó más y solo se alimentaba con lo que compraba ocasionalmente en algún puesto de comida con el que tropezaba en sus caminatas. Cansado [...] como un autómata» (202). Los motivos que permiten a Reyes sobrellevar estas duras pruebas se relaciona con el amor por Aurora y el deseo de convertirse en un hombre libre; en ocasiones, el protagonista imagina que: «Volvería a ser dueño de su vida, de su destino, sería un hombre libre, con un complejo y largo proceso por delante, que para llevarlo a cabo necesitaría la ayuda de muchas personas, la primera de ellas Aurora» (184).

El encuentro con la diosa requiere de un nuevo sacrificio por parte de Mauricio; el protagonista debe ofrendar su dignidad. Rechazado por ambos bandos de la disputa, Aurora no ha dado muestras de interesarse por Mauricio, ni siquiera se acerca a la conferencia de prensa. El héroe considera este nuevo repudio: «Caviló mucho sobre la ausencia de Aurora, por su indiferencia, y se sintió muy solo y angustiado, desamparado de la mujer que amaba, quien no le tendía una mano en el momento en que más la necesitaba» (184). 
La ausencia de Aurora conduce a nuevos estadios del viaje del héroe, se trata de aquellos pasajes denominados por Campbell ${ }^{19} \mathrm{con}$ los títulos «la mujer como tentación» y «la reconciliación con el padre». Tras afrontar las difíciles pruebas, el héroe se vuelve más fuerte y descubre que poseer a la mujer-diosa lo coloca en la posición del padre. Esta condición lo mueve a reconciliarse con la figura de poder. En el relato literario, Mauricio no logra poseer por completo a Aurora, cuya ausencia atribuye a la ruina en que él se halla. La condición de traidor de la causa revolucionaria y esbirro de los déspotas lo vuelve una figura deleznable.

No obstante, Reyes emprende un ejercicio de reconciliación con el pasado. Como parte de este, compone unas memorias acerca de su paso por la guerrilla. La escritura le permite comprender sus circunstancias, por lo que se dedica por entero a este afán de memoria: «En medio de la incertidumbre que vivía, se dedicó a escribir con frenesí» (198). En tanto figura marcada por el patetismo, el protagonista no logra superar por completo sus pruebas; aunque lo intenta, no puede poseer a la diosa, pero alcanza la apoteosis y última gracia.

La gracia final le viene del conocimiento que adquiere respecto de la ausencia de Aurora. Antes de terminar sus días en un apartamento en Zacamil, Mauricio decide escribir y entregar una carta destinada a Aurora. Busca las oficinas del diario donde trabaja la amada y descubre la suerte de la mujer, pues ante la solicitud de dar curso a la carta, un empleados afirma: «-Con gusto se la daría, [la carta] pero ella no trabaja en esta empresa -dijo insinuando una sonrisa- Es cierto, aquí trabajó pero hace un tiempo murió» (208). Mauricio no se había enterado de que, un día después de su encuentro en Perquín, Aurora había sido asesinada por un hombre encapuchado en su apartamento. Ella volvía de El Heraldo la noche de ese domingo y fue sorprendida por un criminal que la estranguló Así, para el héroe, se desvanece su único soporte.

19 Campbell, 114-138. 


\section{Último paso: el regreso}

El regreso es, al igual que el proceso de la iniciación, un tanto accidentado. Por lo general, el héroe primero experimenta una actitud negativa, pues no desea regresar al lugar de donde salió; luego emprende una suerte de huida mágica o un rescate, que le hace remontar el umbral y verse en posesión de dos mundos distintos, ahora, con plena libertad para vivir. En la novela de Rojas, Mauricio Reyes, abandonado, no podrá superar la desolación de verse sin Aurora, pero tampoco pensará en regresar a la guerrilla (negativa del regreso):

Consumido por la soledad, la desesperación y el decaimiento, Mauricio no vislumbraba salida alguna a la crisis $[\ldots]$. Esperaba únicamente que bajara la tensión militar para salir de aquel lugar $[\ldots]$ y huir posiblemente a un campo de desplazados a implorar auxilio. Analizaba también la posibilidad de pedir ayuda a un organismo de derechos humanos, pero estos, generalmente, proclives ideológicamente a la guerrilla, estaban comprometidos con su proyecto político y no darían auxilio a un desertor (215-216).

En el texto literario, la huida mágica resulta de las acciones de jóvenes simpatizantes de la guerrilla, que encuentran a Mauricio vagando por la calles de San Salvador: «Anochecía cuando entró en el Bulevar de Los Héroes [...] no supo de dónde ni en qué momento surgió un hombre joven [...]. Discretamente entre la abotonadura de su chaqueta de cuero negro, uno de ellos asomó en cañón de un revolver» (229). El rescate de la desolación del mundo exterior equivale, para Reyes, a una sentencia de muerte.

Los captores conducen al protagonista de vuelta a un campamento de la guerrilla. El viaje a los orígenes no se corresponde con un proceso de recuperación ni de reintegración, es llanamente la disolución de un estadio distinto de la guerra, un estadio inspirado por amor. Mauricio cruza el umbral en un vehículo todo terreno azul; ha logrado conocer dos mundos distintos: ha vivido y luchado por 
sobrevivir entre guerrilleros, ha sido víctima del gobierno. Paria del sector conservador, traidor para los revolucionarios:

-Un tribunal popular te ha sentenciado a la pena de muerte. Debés ser fusilado por traidor, por las personas inocentes que han muerto por tu culpa, por haber pasado información confidencial al enemigo, información que solo tienen nuestros compañeros de confianza [...]. Con la mirada clavada en el suelo, Mauricio no reaccionó. Ni intentó hablar. Únicamente unas lágrimas rezagadas brotaron de sus ojos y rodaron por sus mejillas costrosas de tierra, sangre y sudor (232).

El héroe ha llegado al término de la aventura. En la juventud, emprendió una lucha política con el afán de transforma la realidad social: «No estaba renunciando a los principios políticos y sociales que habían sido el norte de su vida. Desde cualquier otra trinchera seguiría luchando por una mejor sociedad, con equidad, respetuosa de los derechos de todas las personas sin importar su condición social y su forma de pensar» (25). En la vida adulta, quiso ser señor de su propia conciencia. En el mundo representado en la novela no hay cabida para estados intermedios; en el enfrentamiento, privan los bandos.

Juan Ramón Rojas acude a fantasías primordiales y estructuras míticas con el propósito de problematizar el acto de la toma de conciencia individual, el desencanto político y la disyuntiva entre el bien común y el bienestar individual. La novela contemporánea no escapa de las formas básicas; la novela Desertor es un claro ejemplo de ello. El proceso cifrado en el relato, independización y autodefinición del protagonista, adquiere sentido cuando se lo examina bajo el esquema del viaje de iniciación.

La figura de Mauricio Reyes, quien huye de la guerrilla para reencontrarse con el amor, es un personaje atípico en la novelística centroamericana acerca del conflicto armado. El motivo del traidor da forma a un carácter propio de la época reciente, una figura moldeada a partir de los criterios del desencanto y la individualidad, distante del fervor revolucionario que determina a buena parte de la 
producción literaria de los autores iniciados en el oficio durante la década de 1980.

El patetismo del héroe da cuenta de una clase distinta de relato. Si bien el atrevimiento de Mauricio Reyes parece ser objeto de castigo; en la novela, el protagonista se convierte en un faro para sus iguales. Mauricio, en tanto héroe, renacerá con la lectura del diario, de las memorias afanosamente escritas. Después de la muerte del protagonista, el manuscrito es hallado por otro guerrillero: «Juan, el jefe del grupo, esperando que la noche les diera alguna posibilidad de escapar sin ser detectados, comenzó a leer un asombroso manuscrito titulado El yunque y el martillo, lleno de detalles» (238). 